\title{
Use-Dependent Exaggeration of Neuronal Injury after Unilateral Sensorimotor Cortex Lesions
}

\author{
Dorothy A. Kozlowski, Debra C. James, and Timothy Schallert \\ Department of Psychology and Institute for Neuroscience, University of Texas at Austin, Austin, Texas 78712
}

\begin{abstract}
Unilateral injury to the forelimb representation area of the sensorimotor cortex (FL-SMC) in adult rats causes over-reliance on the unimpaired forelimb for postural-motor movements, as well as overgrowth of layer $\mathrm{V}$ pyramidal cell dendrites in the homotopic cortex of the noninjured hemisphere. The overgrowth appears to be use-dependent because it can be prevented by restricting movements of the unimpaired forelimb. Additionally, restricting the unimpaired forelimb in animals with FL-SMC damage results in significantly greater behavioral dysfunction when examined $2 \mathrm{~d}$ after cast removal (compared to that after impaired-limb immobilization, or no limb immobilization). In the present study, the long-term behavioral and anatomical effects of limb immobilization were examined. Animals with FL-SMC lesions were fitted with casts immediately after the lesion that immobilized the impaired forelimb, the unimpaired forelimb, or neither forelimb for $15 \mathrm{~d}$. Immobilization of the nonimpaired forelimb resulted in chronic prevention of dendritic growth and
\end{abstract}

severe and chronic behavioral deficits. In addition, immobilization of the nonimpaired forelimb resulted in a dramatic exaggeration of the neuronal injury, presumably attributable to forced overuse of the impaired limb. Immobilization of the impaired forelimb resulted in no detectable neural changes and in only slightly increased and longer-lasting behavioral asymmetries (compared to nonimmobilized, lesioned animals), presumably attributable to mild disuse of the impaired limb. Immobilization of a single forelimb in nonlesioned rats resulted in no significant behavioral or anatomical changes. Together, these results suggest that although behavioral experience can enhance neural growth after brain injury, the region surrounding the injury may be vulnerable to behavioral pressure during the early postlesion period.

Key words: recovery of function; stereology; use-dependent; sensorimotor cortex; forelimb immobilization; neuronal degeneration
Unilateral injury to the forelimb-representation area of the sensorimotor cortex (FL-SMC) in adult rats leads to biphasic neuroanatomical events in the intact, contralateral, homotopic cortex: use-dependent increase in the number of dendritic branches observed in layer $\mathrm{V}$ pyramidal cells (which may reflect dendritic growth), followed by glutamate-dependent reduction of the dendritic branches (which may reflect dendritic pruning) (Jones and Schallert, 1992, 1994; Kozlowski et al., 1994; Schallert and Jones, 1994). Dendritic enhancement is maximal in tissue examined $18 \mathrm{~d}$ after surgery, and dendritic reduction occurs thereafter. The enhancement of dendritic processes has been linked to a lesioninduced hyper-reliance on the unimpaired forelimb (i.e., the forelimb opposite the neuronal morphological changes; Jones and Schallert, 1994). When one-sleeved casts were used to prevent animals with an FL-SMC lesion from using their unimpaired forelimb during the period of expected overgrowth, lesioninduced dendritic enhancement was not present when examined $2 \mathrm{~d}$ after cast removal. This manipulation also interfered with performance on experience-dependent tests of postural-motor function also examined $2 \mathrm{~d}$ after cast removal (Jones and Schallert, 1994). Forcing nonlesioned (sham-operated) animals to use only one limb did not detectably alter dendritic morphology and

Received Dec. 8, 1995; revised April 11, 1996; accepted April 16, 1996.

This work was supported by NS 23964, AA 07471, and Grant NS30308 from the Lind Lawrence Foundation. We thank Rebecca Cody, Alycia Halliday, Jeffrey Gotts, J. Leigh Humm, and Angela Krepps for their assistance in behavioral testing, data collection, and surgery.

Correspondence should be addressed to Dorothy A. Kozlowski, UCLA Medical Center, Division of Neurosurgery, 18-228 NPI, P.O. Box 957039, Los Angeles, CA 90095.

Copyright (C) 1996 Society for Neuroscience $0270-6474 / 96 / 164776-11 \$ 05.00 / 0$ did not cause behavioral impairments. Thus, dendritic growth may be associated with an interaction between brain injury and learning-dependent use of the intact forelimb in compensating for lesion-induced deficits in the impaired forelimb.

The present study examined the long-term anatomical and behavioral consequences of immobilizing the unimpaired forelimb (i.e., forcing use of the impaired forelimb). The unimpaired forelimb in lesioned rats was immobilized with a one-sleeved cast during the period of dendritic enhancement (days 1-15 postlesion). After the casts were removed, behavioral events and neural morphology were examined at different time points. The initial aim of the study was to address whether there was an optimal period for lesion-induced changes in the contralateral homotopic cortex and for behavioral recovery. Specifically, would the enhancement of dendrites resume after removal of the cast, following the same time course and achieving the same level observed immediately after a unilateral lesion; and would animals that were prevented from using their unimpaired limb (forced to use only their impaired limb) during the first 2 weeks postlesion regain symmetrical forelimb use and recover from deficits in posturalmotor and sensorimotor tasks? Finally, the long-term effects of limb immobilization on the lesioned area were examined using stereological analysis for the first time.

\section{MATERIALS AND METHODS}

\section{Animals}

One-hundred and eighteen male, hooded Long-Evans rats weighing between 400 and $600 \mathrm{gm}$ were used. Rats were individually housed in clear Plexiglas cages with wire bottoms and maintained on a $12 \mathrm{hr}$ light/dark cycle. Food and water were available ad libitum. Animals were 
tamed by gentle handling for at least $5 \mathrm{~min} / \mathrm{d}$ for 3 weeks before surgery and behavioral testing.

\section{Surgical procedures}

Before being placed in a stereotaxic apparatus, the animals were anesthetized with Equithesin $(25 \mathrm{mg} / \mathrm{kg}$ pentobarbital and $150 \mathrm{mg} / \mathrm{kg}$ chloral hydrate, $0.35 \mathrm{cc} / 100 \mathrm{gm}$, i.p.) followed by atropine sulfate $(0.1 \mathrm{mg} / \mathrm{kg}$, i.p. $)$ to facilitate respiration. A unilateral lesion of the FL-SMC (Hall and Lindholm, 1974; Neafsey et al., 1986; Wise and Donoghue, 1986) was performed $(n=67)$ by removing a piece of the skull between 3.0 and 4.5 $\mathrm{mm}$ lateral to midline, $-0.5 \mathrm{~mm}$ posterior, and $+1.5 \mathrm{~mm}$ anterior to bregma to pass a $1 \mathrm{~mA}$ current through a platinum electrode lowered 1.7 $\mathrm{mm}$ below dura. The current was delivered during equally spaced traverses through the exposed cortex for a total of $2 \mathrm{~min}$. Sham-operated animals $(n=51)$ received all standard stereotaxic surgical procedures up to, but not including, removal of the skull. After surgery, all animals were placed in incubators to minimize hypothermia.

\section{Forelimb immobilization (casting) procedures and treatment groups}

Animals were randomly assigned to one of four treatment groups: (1) Lesion + Ipsilateral (to the lesion) Cast (Lesion+Ipsi), (2) Lesion + No Cast (Lesion+No), (3) Sham + Cast (Sham+Cast), and (4) Sham + No Cast $($ Sham + No). They were also randomly assigned to be killed at one of three time points: on day 18 (Lesion $+\mathrm{Ipsi}, n=10$; Lesion + No, $n=9$; Sham + Cast, $n=9$; Sham + No, $n=8$ ), day 33 (Lesion+Ipsi, $n=11$; Lesion + No, $n=9$; Sham + Cast, $n=9$; Sham + No, $n=8$ ), or day 60 (Lesion+Ipsi, $n=10$; Lesion +No, $n=8$; Sham + Cast, $n=9$; Sham + No, $n=8)$ postlesion. These time points were chosen to correspond to the time course of dendritic enhancement seen immediately after a lesion: (1) day 18 was the time at which maximum dendritic enhancement was seen in noncasted lesioned animals previously demonstrated in Jones and Schallert (1992, 1994); (2) day 33 was 18 d after cast removal, which was the number of days sufficient, immediately after a lesion, for dendritic enhancement to occur; and (3) day 60 was $45 \mathrm{~d}$ after cast removal, the number of days necessary immediately after a lesion for dendritic pruning to occur). An additional group of rats was assigned to a Lesion + Contra (to the lesion) cast (Lesion+Contra, $n=10$ ) and killed on day 60. This group was added to examine the long-term behavioral consequences of immobilizing the impaired limb. Dendritic morphology was not examined in these animals because in previous work it was shown that this procedure did not impair dendritic growth in the intact hemisphere (Jones and Schallert, 1994).

Immediately after surgery, animals in the "cast" groups were fitted with casts composed of plaster of paris designed to immobilize the designated limb. The designated forelimb was placed in a naturally retracted position against the sternum, and strips of casting material were formed around the limb and upper torso until they resembled one-sleeved jackets (Jones and Schallert, 1994). A small, loose stitch was placed connecting the back of the cast to the back skin of the rat to ensure placement and discourage removal of the cast. The casts were removed at day 15 postsurgery. During the $15 \mathrm{~d}$ cast period, the animals were groomed daily with cotton swabs and brushed to maintain a healthy coat.

\section{Histological procedures}

On day 18,33 , or 60 , postsurgery animals were given a lethal dose of sodium pentobarbital anesthesia $(1.0 \mathrm{ml})$ and perfused intracardially with saline followed by a $10 \%$ formalin solution. The brains were extracted, quartered, and placed in Golgi-Cox solution for 3 weeks. Following reaction and dehydration procedures adapted from Ramon-Moliner (1970), each cerebral hemisphere was embedded separately in epoxy resin and sliced on a microtome into $240 \mu \mathrm{m}$ sections separated by $150 \mu \mathrm{m}$ sections and mounted on slides. The slides were encoded by an independent researcher before quantification to minimize experimenter bias.

\section{Analysis of the intact hemisphere}

Dendritic quantification. Slices between $2.0 \mathrm{~mm}$ anterior to bregma and $1.0 \mathrm{~mm}$ posterior to bregma were chosen for quantification based on previous examination of the placement of the forelimb area in Nisslstained sections (Jones and Schallert, 1989). This area encompasses approximately three to four slices. Pyramidal neurons from cortical layer $\mathrm{V}$ from the region between the dorsal peak of the corpus callosum and 4.0 $\mathrm{mm}$ lateral to midline were chosen from each of these slices based on absence from obstruction by astrocytes, capillaries, or neural processes of neighboring pyramidals and drawn using a camera lucida at $475 \times$ magnification. The number of basilar dendritic branches was counted for 10 neurons per brain.

\section{Analysis of the lesioned hemisphere}

Volume analysis. To analyze differences in lesion size, the volume of the lesioned hemisphere and the hemisphere ipsilateral to the designated "sham" side was estimated using the Cavalieri principle. This has been found to be an unbiased and highly efficient method of analyzing the volume of regularly shaped objects (for review, see Uylings et al., 1986; Royet, 1991). Unbiased estimates of area were made using systematic point counting from coronal sections between approximately +2.7 and $-1.3 \mathrm{~mm}$ (inclusively) relative to bregma. This area encompassed the forelimb motor representation area and surrounding cortex. A grid of points $2.0 \mathrm{~cm}$ apart was placed in a random position over $20 \times$ projections of these coronal sections in the hemisphere of interest. Volume estimates were computed using the formula $V=T \times(a / p)^{2} \times \Sigma P$, where $V$ is the estimated volume, $T$ is the distance between the face of section " $n$ " and the face of section " $n+1$ " $(390 \mu \mathrm{m}), a / p$ is the area per test point, adjusted for magnification $(20 \mathrm{~cm} / 20 \times \text { magnification })^{2}$, and $\Sigma P$ is the total number of points found to touch brain tissue throughout all sections (Gundersen and Jensen, 1987; Korbo et al., 1990). The coefficient of error (SD/mean) (Gundersen and Jensen, 1987; West and Gundersen, 1990) was $<0.06$ for each estimate. Animals from the following groups were excluded from this analysis because of gouges or tears in the tissue or poor sections: Lesion+Contra $(n=2)$; Lesion+Ipsi $(n=1)$; Lesion+No $(n=1)$; Sham $(n=5)$.

\section{Behavioral testing and limb use observations}

A battery of behavioral tests was administered before surgery, $6-8 \mathrm{hr}$ after removal of the cast at day 15 , and then on postlesion days 17, 24, 31, $38,45,52$, and 59. Additionally, limb-use observations were performed presurgery and on postlesion days $2,4,7,10,15(6-8 \mathrm{hr}$ after cast removal), 17, 24, 31, 38, 45, 52, and 59. The following tests have been shown to be sensitive to unilateral FL-SMC lesions and have been associated with experience-dependent anatomical changes such as dendritic growth (Jones and Schallert, 1992, 1994; Schallert and Jones, 1994; Jones et al., 1995, 1996).

\section{Forelimb placing}

Asymmetries in forelimb-placing behaviors were assessed using the Forelimb Placing Test. Animals were held by their torso with their forelimbs hanging freely. Each forelimb was tested independently by orienting one side of the animal toward a countertop and moving the animal slowly and laterally toward the edge of the countertop until the vibrissae of that side made contact with the edge. Intact rats typically place the forelimb (both ipsilateral and contralateral forelimbs) quickly onto the edge of the counter. Lesioned animals, on the other hand, typically place the limb ipsilateral to the lesion but show difficulties with the contralateral limb. Ten trials of each forelimb were performed in a balanced order. Placing asymmetries were recorded as the percent unsuccessful contralateral placements.

\section{Limb use observations}

Asymmetry in forelimb use was observed by videotaping the rat in a three-sided Plexiglas platform $\left(53 \times 16 \times 26.5 \mathrm{~cm}^{3}\right)$ for $4 \mathrm{~min}$. Observations were made of the forelimb used for support during the following behaviors: during push off from the floor before rearing, during support behaviors against the walls of the platform both in the vertical and horizontal direction, and during landing after a rear. Jones and Schallert $(1992,1994)$ have found that these behaviors are easily quantified, frequently observed in both nonlesioned and lesioned rats, observed in both the home cage and on the platform with equal frequency, and appear to represent important and typical motor behaviors of rats. Limb use is presented as percent ipsilateral forelimb use.

\section{Experience-independent test of somatosensory asymmetry}

The bilateral tactile stimulation test and the somatosensory neutralization tests (Schallert et al., 1983; Schallert and Whishaw, 1984) were used to measure forelimb somatosensory asymmetries.

The animals were removed from their home cages, and small adhesive backed patches $\left(113.1 \mathrm{~mm}^{2}\right)$ were applied to the radial aspect of the wrist of both forelimbs. The rats were returned to their home cages, and the order and latency in which the animal contacted and removed the stimuli 
were recorded. Four to five trials were conducted. Each trial was terminated after removal of both stimuli or after $2 \mathrm{~min}$ had passed. If the animal contacted and removed stimuli from only one side in $80-100 \%$ of the trials, a second phase of the test, somatosensory neutralization, was administered to assess the magnitude of the asymmetry. Preoperatively, if an animal showed a preference for stimuli placed on a given forelimb, the lesion was placed in the opposite hemisphere so that the postoperative effects were not masked by any endogenous asymmetry. Animals without a preoperative preference were randomly assigned to a lesion side.

In the somatosensory neutralization test, the stimulus on the limb ipsilateral to the response bias was decreased by $14.1 \mathrm{~mm}^{2}$ while the stimuli contralateral to the response bias was increased by $14.1 \mathrm{~mm}^{2}$. The ratio of the ipsilateral to the contralateral stimulus necessary to reverse or neutralize the response bias (e.g., the animals contact the contralateral and not the ipsilateral stimulus first) was recorded as the magnitude of asymmetry.

Unlike limb use and forelimb placing, the standard bilateral-tactile stimulation test is not influenced by experience. In a study by Schallert and Whishaw (1984), one group of lesioned animals was tested daily for 2 weeks, which provided an opportunity to practice the particular task; another lesioned group was not tested until the end of the 2 week period. Both groups received the same score (magnitude of asymmetry), suggesting that practice does not affect performance on this test. In another study, Rose et al. (1987) showed that this test, which they termed a test of "true recovery," was not affected by postlesion enrichment. Additionally, studies have shown that this test does not correlate well with experience-induced alterations in neural morphology (Jones and Schallert, 1992, 1994).

\section{Statistical analyses}

Data analysis was accomplished by SAS procedures for general linear models with unequal cell sizes. Dendritic branches and volume data were analyzed by a two-factor ANOVA for Condition $\times$ Day of Killing treating neurons as nested variables within subjects for the dendritic analysis. Additionally, one-way ANOVAs for Group were performed at each time point. Post hoc analyses were conducted using SAS univariate contrasts for simple effects of Group and for simple effects of Group at different days postlesion.

Statistical analyses of behavioral data were conducted using SAS procedures for general linear models with unequal cell sizes. Behavioral data were analyzed at each separate time point with a repeated-measure, two-factor ANOVA for Group (i.e., treatment condition: Lesion+Ipsi, Lesion + No, Sham + Cast, Sham + No) $\times$ Day of behavioral observation (repeated measure). For each of the behavioral tests, performance on days 17 and 31 was analyzed individually for each group with a one-way ANOVA for Time Course (day 18, 33, or 60) to determine whether there were differences in behavior based on the time course group to which they were assigned. No significant differences of time course were found. Therefore, to best illustrate the behavioral recovery process, behavioral data from only the day 60 time course group are presented. Post hoc analyses were conducted using SAS univariate contrasts for simple effects of group at different test days.

\section{RESULTS}

\section{Histological analysis of the intact hemisphere}

\section{Dendritic growth}

The number of basilar dendritic branches in Golgi-stained neurons examined at day 18,33 , or 60 postlesion is presented in Figure 1. There have been concerns regarding the use of the Golgi stain to measure dendritic growth, specifically that it does not fully fill the dendritic tree, thus providing a biased measure. However, this method has consistently differentiated between lesioned and nonlesioned animals in numerous studies conducted in our laboratory and elsewhere (Kolb, 1995). In addition, dendritic growth and morphological changes in dendrites have been analyzed further in lesioned versus nonlesioned animals using electron microscopy (Jones et al., 1995, 1996). This study supported the idea that a unilateral lesion to the FL-SMC results in time-dependent dendritic growth in layer $\mathrm{V}$ of the contralateral homotopic cortex as predicted by the Golgi stain. By day 18 postinjury, a significant increase was seen in the volume of dendritic processes per neuron

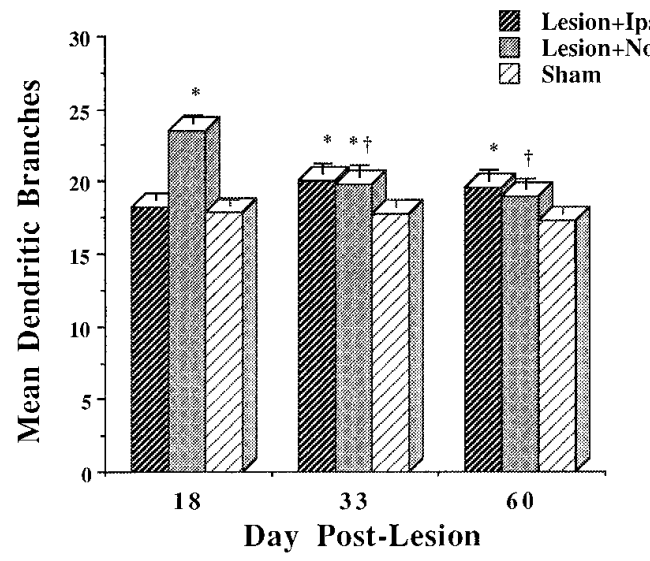

Figure 1. Mean dendritic branches in layer V pyramidal neurons in the intact, contralateral, homotopic cortex. At day 18 , Lesion+ No cast $($ Lesion $+\mathrm{No})$ animals show an increase in dendritic growth compared with shams. This enhancement of dendritic morphology is blocked by immobilization of the ipsilateral forelimb. When the cast is removed and the animals are killed 18 and $45 \mathrm{~d}$ after cast removal (days 33 and 60 postlesion, respectively), there is a slight, but not significant, increase in dendritic growth. Additionally, the dendritic growth does not reach Lesion + No cast levels seen at day 18. Lesion + No cast animals show the previously demonstrated increase in dendritic growth followed by a decrease or pruning to near sham levels. ${ }^{*} p<0.001$, significantly different from Sham; ${ }^{\dagger} p<0.05$, significantly different from Lesion + No group at day 18.

and in the surface area of dendritic membrane in lesioned animals in comparison to shams, thus suggesting dendritic growth. This was followed by an increase in synapse number per neuron.

In the current study, statistical analysis at all three time points indicated that there were no significant differences between Sham groups (i.e., forcing a nonlesioned animal to preferentially use one forelimb did not result in a change in dendritic growth). Therefore, both Sham + No and Sham + Cast groups were pooled and labeled "Sham" (day 18: $F_{(1,15)}=3.18, p=0.09$; day 33: $F_{(1,15)}=$ $0.28, p=0.60$; day 60: $\left.F_{(1,15)}=0.00, p=0.99\right)$.

At day 18, $3 \mathrm{~d}$ after cast removal, one-way ANOVA revealed a significant effect of Group $\left(F_{(2,32)}=39.60, p<0.0001\right)$. Significant enhancement of basilar dendritic branches was seen in Lesion+No animals (compared to sham, $p<0.0001$ ) as in Jones and Schallert (1992). In addition, immobilization of the forelimb contralateral to the area of dendritic growth prevented the dendritic enhancement (i.e., dendritic levels were no different than those of sham animals; Jones and Schallert, 1994).

At day 33 (18 d after cast removal), of interest was whether the Lesion + Ipsi animals showed any increase in dendritic growth and, if so, whether it was similar to the levels seen in Lesion+No animals at day 18. One-way ANOVA revealed a significant effect of Group $\left(F_{(2,29)}=3.58, p<0.04\right)$. Dendritic pruning began to occur in the Lesion + No group, but the number of branches was increased relative to that of sham animals $(p<0.04)$. The Lesion + Ipsi group showed a slight increase in dendritic arborization that was significantly greater than that of shams $(p<0.02)$, but not greater than Lesion + No; however, the increase did not reach the extent seen in Lesion+No animals at day 18 (even though the animals had $18 \mathrm{~d}$ after cast removal to permit growth, which was the number of days necessary for maximum dendritic enhancement in lesioned, noncasted animals).

By day 60, the dendrites in the Lesion+No group "pruned back" nearly to that of sham levels, but the dendrites in the 


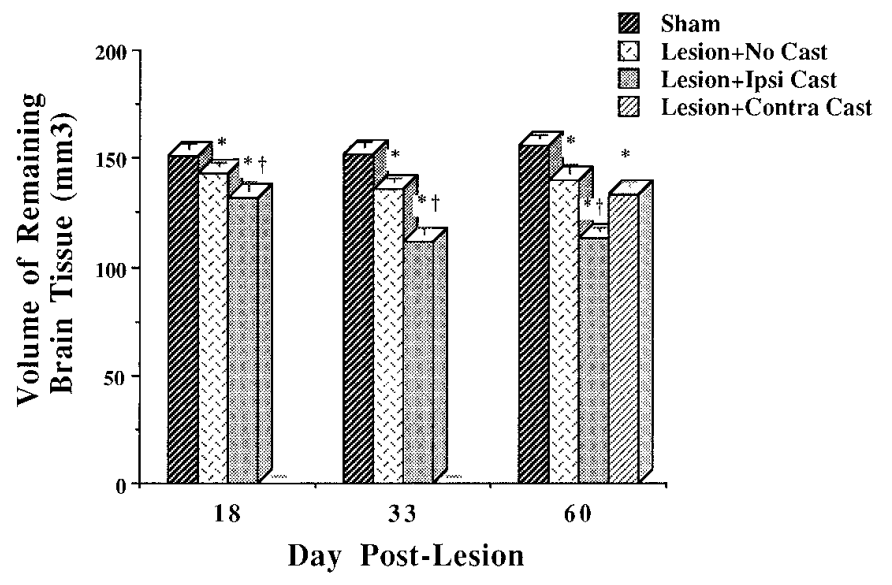

Figure 2. Volume of remaining brain tissue (in $\mathrm{mm}^{3}$ ). Immobilization of the ipsilateral forelimb (i.e., overuse of the impaired limb; Lesion+Ipsi Cast) resulted in a significantly larger lesion (less remaining brain tissue) compared with Lesion+No Cast, Lesion +Contra Cast, and Sham groups. Immobilization of the contralateral forelimb resulted in no significant differences in lesion volume compared with Lesion+No animals. ${ }^{* \dagger} p<$ 0.0001 , significantly different from Sham and Lesion+No groups; ${ }^{*} p<$ 0.0001 , significantly different from Sham.

Lesion + Ipsi group remained at the level seen at day 33, which was significantly different from sham $(p<0.005)$.

Group $\times$ Day analysis revealed no significant effect of Day for the Lesion+Ipsi and the Sham groups $(p=0.16$ and $p=0.61$, respectively), suggesting that no significant changes in dendritic growth occurred over the three time periods. Therefore, immobilization of the nonimpaired forelimb prevented dendritic growth and dendritic arborization did not change over time. The failure to find a change in dendritic branching over time in the Sham group suggests that the changes in dendritic arborization over time in lesioned animals cannot be attributed to an age effect. In the Lesion+No group, there was a significant effect of Day $\left(F_{(2,22)}\right.$ $=10.52, p<0.006)$. Noncasted, lesioned animals showed an enhancement of dendritic growth followed by a "pruning" of dendrites, as demonstrated previously in Jones and Schallert (1992).

\section{Histological analysis of the lesioned hemisphere}

\section{Lesion volume}

Brain volume measures did not differ between casted and noncasted sham-operated animals at day $18\left(F_{(1,14)}=0.14, p=0.71\right)$, day $33\left(F_{(1,12)}=0.73, p=0.41\right)$, and day $60\left(F_{(1,14)}=0.19, p=\right.$ $0.67)$. Therefore, Sham + Cast and Sham + No groups were pooled and labeled "Sham."

One-way ANOVA revealed significant effects of Group at day $18\left(F_{(2,32)}=19.71, p<0.0001\right)$, day $33\left(F_{(2,29)}=96.27, p<\right.$ $0.0001)$, and day $60\left(F_{(3,38)}=83.43, p<0.0001\right)$ postlesion. As Figure 2 illustrates, there was a significant difference between all lesioned animals and sham animals at all three time points $(p<$ 0.01 ). This indicated that there was significantly less brain tissue remaining in lesioned animals than in sham animals. In addition, there was a significant difference between Lesion+Ipsi and Lesion + No animals at day $18\left(F_{(1,32)}=9.38, p<0.004\right)$, day 33 $\left(F_{(1,29)}=52.39, p<0.0001\right)$, and day $60\left(F_{(1,38)}=76.02, p<\right.$ $0.0001)$. Lesioned animals that had their nonimpaired limb immobilized (i.e., were forced to use their impaired limb) had significantly less brain volume than lesioned animals with no limb immobilization (i.e., the size of their lesion increased). However, there was no difference in lesion size between lesioned animals that had their impaired forelimb immobilized (Lesion+Contra) and uncasted lesioned animals $\left(F_{(1,38)}=3.16, p=0.12\right)$ at day 60 . In summary, immobilization of the ipsilateral limb in lesioned animals, which may be associated with forced use of the impaired limb, resulted in a significantly larger lesion than in lesioned animals with immobilization of the contralateral limb, lesioned animals with no limb immobilization, and sham animals (with or without limb immobilization). The enhanced lesion size associated with casting the nonimpaired forelimb, which forces overuse of the impaired limb, may reflect a novel experimental finding: "use-dependent" exaggeration of neuronal injury.

The apparent size of the lesion in Lesion+Ipsi animals progressively increased over time $(p<0.05)$ (See Fig. 3). At day 18, the difference was not obvious on inspection, via qualitative comparisons using a microprojector (see also Jones and Schallert, 1994). Nonetheless, quantitative, stereological measurements resulted in a significantly larger lesion in Lesion+Ipsi animals than in Lesion +No animals at day 18 . By day 33, quantitative (stereological) and qualitative (visual) inspection of the size of the lesion in Lesion+Ipsi animals showed a much larger lesion, expanding laterally, posteriorly, and anteriorly into the surrounding cortex $(p<0.05)$. Also, there occurred an expansion of the ventricle, loss of the corpus callosum, and loss of tissue in the dorso-medial striatum. On day 60, volume estimates indicate that the size of the lesion in Lesion+Ipsi animals was identical to the size at day 33. Nonetheless, there seem to be qualitative differences. At day 60, the borders of the enlarged lesioned area seemed to become more regular, looking as if tissue was "scooped out" of the brain.

Because this tissue was stained using Golgi procedures, a consecutive study was performed in which Lesion+Ipsi $(n=5)$, Lesion + No $(n=5)$, and Sham $(n=4)$ groups were killed at day 33 , and their brains were sectioned using a vibratome $(100 \mu \mathrm{m}$ sections, separated by $300 \mu \mathrm{m}$ ) and stained with cresyl violet (a Nissl stain). Stereological analysis of this tissue showed that the effect was replicated (see Table 1). Additionally, this stain allowed for stereological analysis to be performed on the contralateral versus ipsilateral striatum, the contralateral versus ipsilateral total volume of the VPL, VPM, VLN, and VMN of the thalamus (which sends and receives projections to the SMC), and the contralateral versus ipsilateral sensorimotor cortex. At day 33, in lesioned animals, there was tissue loss in the lesioned cortex, the thalamus ipsilateral to the lesion, and the posterior portion of the striatum ipsilateral to the lesion (bregma -0.3 to -2.3 ). In the Lesion+Ipsi group, the use-dependent degeneration was restricted to the cortical areas at this time point. No differences were seen in the ipsilateral thalamic or striatal volumes between the Lesion + No and the Lesion+Ipsi group even though, on visual inspection, there seemed to be a decrease in size in the striatum. The lack of difference between the Lesion+Ipsi and the Lesion + No groups in the measures of the striatum may be attributable to the observation, in Golgi-stained tissue, of an extensive proliferation of astrocytes in the Lesion + Ipsi animals limited only to the dorsal regions of the striatum, an area that receives direct projections from the somatosensory cortex (Kolb and Tees, 1990). This proliferation was seen at days 18,33 , and 60 . Proliferation of astrocytes is common around injured tissue; therefore, there may be neural degeneration occurring in the striatum that is not detectable by the stains used in this study. Further studies using stains specific to astrocyte proliferation (like GFAP) or neuronal degeneration (like cupric silver) would be beneficial to examine the proliferation of astrocytes in the striatum and the role that it 
Figure 3. Representative photographs of the Golgi-stained lesioned hemisphere in the Lesion+Ipsi $(C-E)$, Lesion+Contra $(B)$, and Lesion + No $(A)$ groups at different time points after injury.
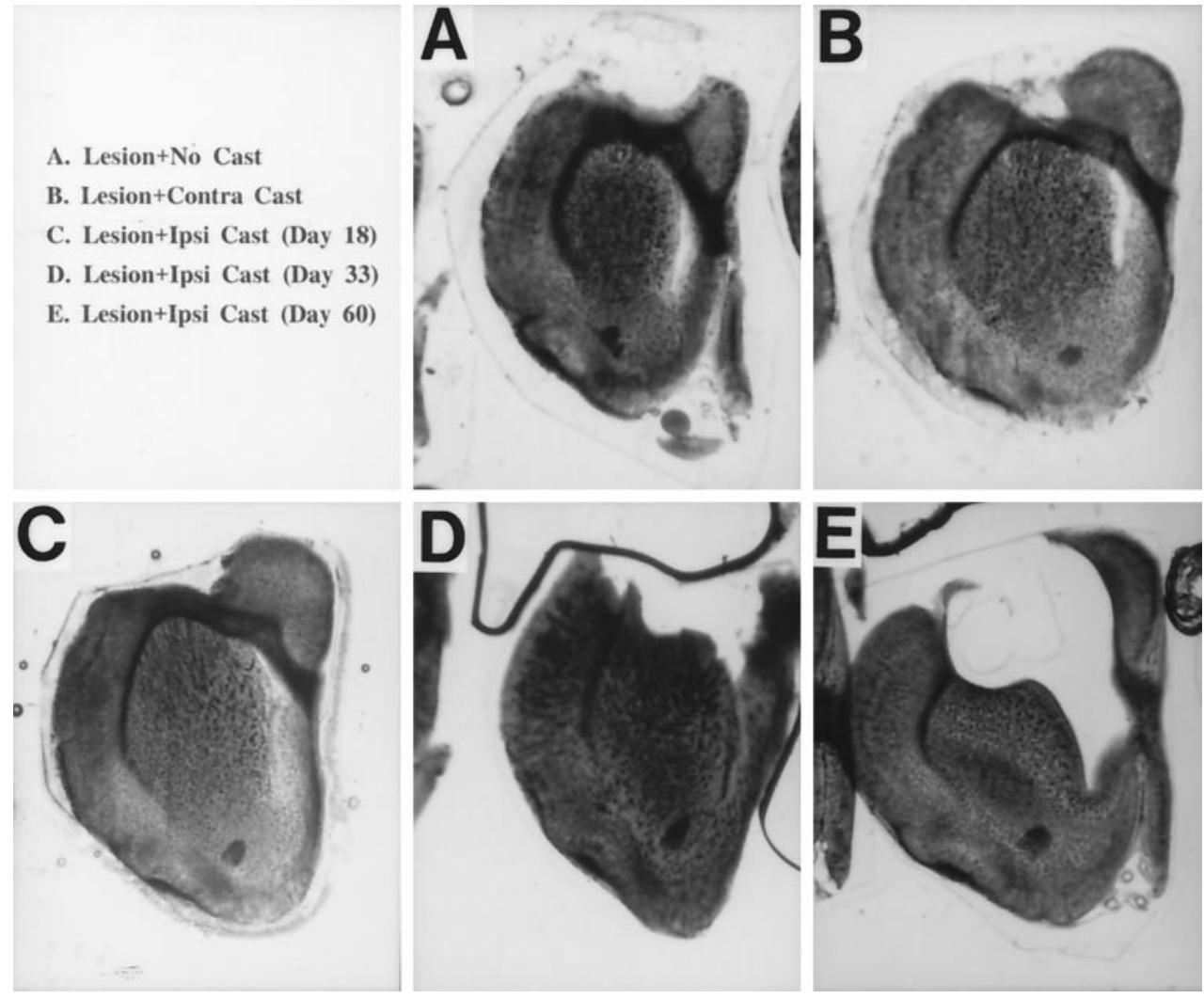

plays. Nonetheless, preliminary microscopic examination of the Nissl-stained striatum showed less staining of neurons in the Lesion+Ipsi group.

\section{Long-term behavioral effects of limb immobilization Cast-weight analysis}

Casts of lesioned and sham animals were weighed and analyzed after removal to eliminate the possibility that behavioral differences might be attributable to variability in the weight of casts. No significant differences were found in cast weight between groups at day 18,33 , or 60 postlesion $\left(F_{(2,26)}=2.37, p=0.11\right)$.

\section{Forelimb placing}

Immobilizing a forelimb in an unlesioned animal (i.e., sham) resulted in no significant behavioral differences between Sham + Cast and Sham + No groups $\left(F_{(1,15)}=1.76, p=0.20\right)$. Therefore, they were pooled and labeled "Sham." Two-way ANOVA revealed a main effect for treatment Group $\left(F_{(3,41)}=\right.$ $119.81, p<0.0001)$, for Day $\left(F_{(8,327)}=74.65, p<0.0001\right)$, and a significant Group $\times$ Day interaction $\left(F_{(24,327)}=27.95, p<\right.$ 0.0001) (See Fig. 4). Post hoc analyses revealed that on the day of, and $2 \mathrm{~d}$ after, cast removal, all lesion groups failed to place their contralateral (to the lesion) forelimb, in comparison to sham animals $(p<0.005)$, which placed both forelimbs successfully $100 \%$ of the time. The placing deficit in the animals whose ipsilateral forelimb was immobilized was significantly greater than in animals whose contralateral forelimb was immobilized or in animals that did not experience limb immobilization $(p<0.005)$. Deficits in contralateral forelimb placing also persisted much longer in the Lesion+Ipsi group than the other two lesion groups. Lesioned animals with no limb immobilization recovered forelimb placing behaviors by day 24 postlesion. At this time, both Lesion+Ipsi and Lesion+Contra groups were still showing con- tralateral placing deficits that were significantly greater than that of both Lesion + No and Sham groups $(p<0.005)$. However, the placing deficit in the Lesion+Ipsi group was significantly greater than that of the Lesion + Contra group $(p<0.0001)$. Contralateral forelimb placing deficits in the Lesion+Contra group persisted slightly longer than those of the Lesion+No group (until day 31 postlesion). The animals in the Lesion+Ipsi group did finally recover forelimb placing behaviors at day 52 postlesion.

\section{Forelimb somatosensory asymmetry}

There were no significant differences between casted and noncasted sham groups in their responses to forelimb somatic sensation; therefore, they were pooled and labeled "Sham" for further analysis. Overall, two-way ANOVA revealed a main effect for treatment Group $\left(F_{(3,41)}=5.88, p<0.002\right)$, for Day $\left(F_{(8,24)}=\right.$ $5.95, p<0.001)$, and a significant Group $\times$ Day interaction $\left(F_{(24,327)}=1.76, p<0.01\right)$. Of primary interest was the chronic effect of the cast manipulations on forelimb somatosensory asymmetries. Post hoc analyses revealed that in the acute period after cast removal (days 15, 17, and 24), animals in both "casted" conditions showed a significantly larger "magnitude of asymmetry" (the ratio of the difference in stimulus size necessary to reverse response bias to bilateral simultaneous tactile stimulation), in comparison to sham animals $(p<0.001)$, but were not significantly different from Lesion + No animals (See Fig. 5). This may have been because immediately after cast removal there was great variability in the response to the previously casted limb in both casted groups (see Jones and Schallert, 1994). In the chronic time period after cast removal (days 31-60), animals that had their ipsilateral forelimb casted maintained a larger magnitude of asymmetry and, therefore, a greater forelimb somatosensory asymmetry compared with shams $\left(F_{(1,41)}=15.65, p<0.0003\right)$, 


\begin{tabular}{|c|c|c|}
\hline \multicolumn{3}{|c|}{ Whole ipsilateral hemisphere } \\
\hline Lesion + Ipsi & $203.5(5.21)^{* \dagger}$ & \\
\hline Lesion + No & $229.6(1.92)^{*}$ & \\
\hline Sham & $254.2(3.29)$ & \\
\hline \multicolumn{3}{|c|}{ Forelimb sensorimotor cortex } \\
\hline Group & Ipsilateral hemisphere & Contralateral hemisphere \\
\hline Lesion+Ipsi & $69.6(8.54)^{* \dagger}$ & $101.1(3.36)$ \\
\hline Lesion + No & $86.9(7.4)^{*}$ & $105.5(1.88)$ \\
\hline Sham & $96.8(2.2)$ & $95.8(1.41)$ \\
\hline
\end{tabular}

Striatum (anterior and posterior)

\begin{tabular}{lll} 
Group & Ipsilateral hemisphere & Contralateral hemisphere \\
\hline Lesion+Ipsi & $25.15(3.16)$ & $27.87(1.25)$ \\
Lesion+No & $26.62(3.2)$ & $29.37(2.17)$ \\
Sham & $26.53(0.75)$ & $26.76(0.85)$
\end{tabular}

Posterior striatum

\begin{tabular}{lll} 
Group & Ipsilateral hemisphere & Contralateral hemisphere \\
\hline Lesion+Ipsi & $19.3(3.15)^{*}$ & $26.3(1.28)$ \\
Lesion+No & $19.3(1.84)^{*}$ & $25.1(2.17)$ \\
Sham & $25.0(0.43)$ & $25.1(0.44)$ \\
\hline
\end{tabular}

Thalamus

\begin{tabular}{lll} 
Group & Ipsilateral hemisphere & Contralateral hemisphere \\
\hline Lesion+Ipsi & $6.90(0.34)^{*}$ & $7.90(0.22)$ \\
Lesion+No & $6.96(0.11)^{*}$ & $7.84(0.39)$ \\
Sham & $8.27(0.71)$ & $8.13(0.32)$
\end{tabular}

Data are presented as mean \pm SE. $* p<0.05$, significantly different from Sham and/or from the contralateral hemisphere; ${ }^{\dagger} p<0.05$, significantly different from Lesion + No.

whereas both the Lesion+Contra and Lesion+No groups showed a forelimb somatosensory asymmetry similar to sham animals (i.e., recovery of a symmetrical response to somatic-sensory stimulation occurred). By the end of the study, $60 \mathrm{~d}$ postlesion, there was a significant difference between Lesion + Ipsi and Lesion + Contra $\left(F_{(1,41)}=6.10, p<0.01\right)$ and between Lesion + Ipsi and Lesion + No groups $\left(F_{(1,41)}=14.08, p<0.0005\right)$. Thus, the magnitude of asymmetrical responses to somatosensory stimulation was similar in all lesion groups immediately after cast removal (in the acute time period after cast removal); however, over time, lesioned animals with the contralateral limb or no limb immobilized recovered symmetrical responding to bilateral tactile forelimb stimulation, whereas the animals with the ipsilateral limb immobilized (those that were forced to use only the impaired limb during the first $15 \mathrm{~d}$ after the FL-SMC lesion) continued to show somatosensory asymmetries that were significantly larger than Lesion+Contra, Lesion+No, and Sham groups.

\section{Limb use}

Noncasted animals with an FL-SMC lesion showed a significant asymmetry in forelimb use immediately postlesion in comparison to shams. The animals with FL-SMC lesions preferred to use their ipsilateral (to the lesion) forelimb for postural-motor support behaviors (70-90\% ipsilateral limb use), whereas sham animals used both forelimbs interchangeably ( $\sim 50 \%$ ipsilateral limb use).

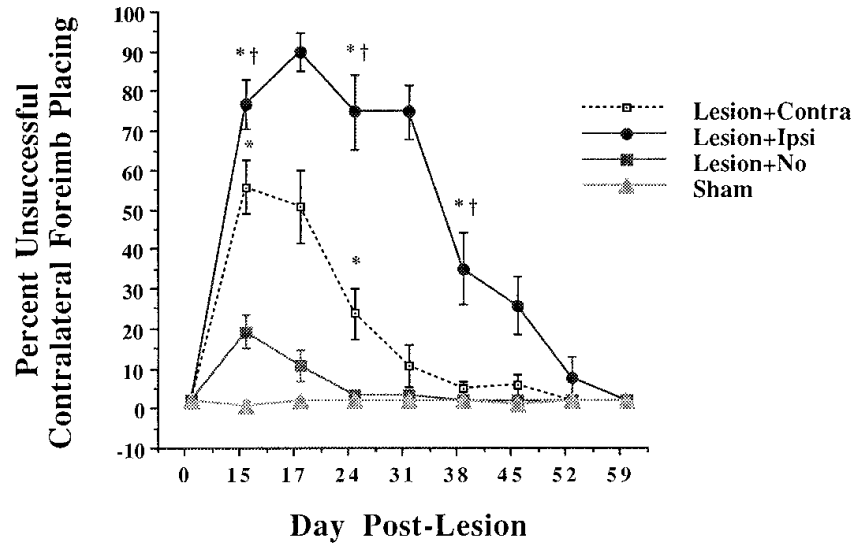

Figure 4. Percent unsuccessful contralateral forelimb placing. After cast removal, Lesion+Ipsi groups (filled circles) showed the largest and longest-lasting deficit. Lesion+Contra animals (open squares) showed a slightly larger deficit, lasting $\sim 14 \mathrm{~d}$ longer, than Lesion+No animals (filled squares), which recovered by approximately day 24 postlesion. ${ }^{\dagger} p<$ 0.001 , significantly different from Lesion + Contra; ${ }^{*} p<0.001$, significantly different from Lesion+ No and Sham.

Two-way ANOVA during the casting period comparing Lesion + No and Sham groups showed a significant effect of Group $\left(F_{(1,14)}=48.28, p<0.0001\right)$, Day $\left(F_{(3,42)}=4.6, p<0.007\right)$, and a Group $\times$ Day interaction $\left(F_{(3,42)}=2.79, p<0.05\right)$. By the end of the study, Lesion + No animals were using their ipsilateral forelimb at sham levels, i.e., $50 \%$ (see Fig. $6 \mathrm{~A}$ ). Immediately after cast removal (days 15 and 17), all casted animals showed preferential use of the noncasted limb (See Fig. 6B). By days 24-31 (acute time period after cast removal), both Lesion+Contra and Lesion+Ipsi groups showed preferential use of the ipsilateral forelimb compared to sham animals $(p<0.001)$, which was greater than the percept ipsilateral limb use seen in Lesion + No animals $(p<0.05)$. Between days 38 and 60 (chronic time period after cast removal), Lesion+Contra animals recovered symmetrical forelimb use to Lesion+No and Sham levels, i.e., $\sim 50 \%$. However, Lesion +Ipsi animals continued to show a preference for ipsilateral forelimb use during postural-motor behaviors, i.e.,

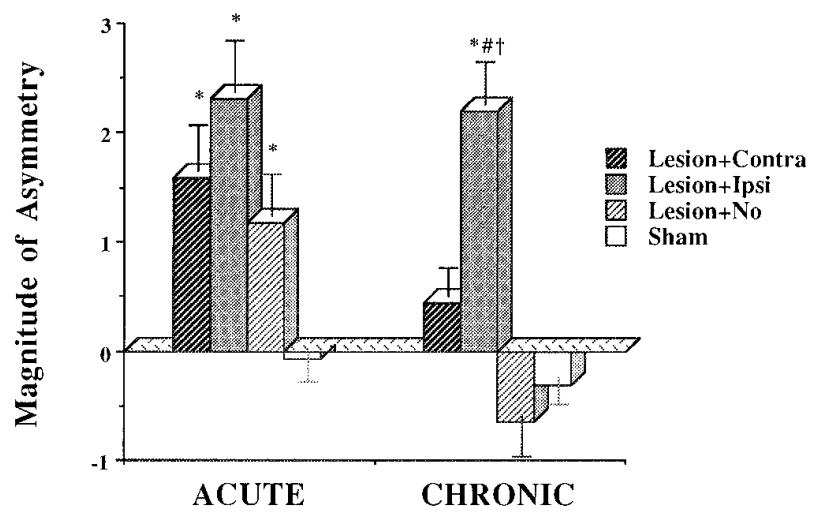

Time Period Following Cast Removal

Figure 5. Magnitude of asymmetry during the acute (days 15-24) and chronic (days 31-60) time periods after cast removal. All lesion groups showed similar magnitudes of asymmetry immediately after cast removal. However, over time Lesion+Ipsi animals showed a persistently larger magnitude of asymmetry that did not recover to Sham levels by the end of the study. ${ }^{*} p<0.05$, significantly different from Sham; ${ }^{*}{ }^{*} p<0.05$, significantly different from Sham, Lesion + Contra, and Lesion+No. 
A

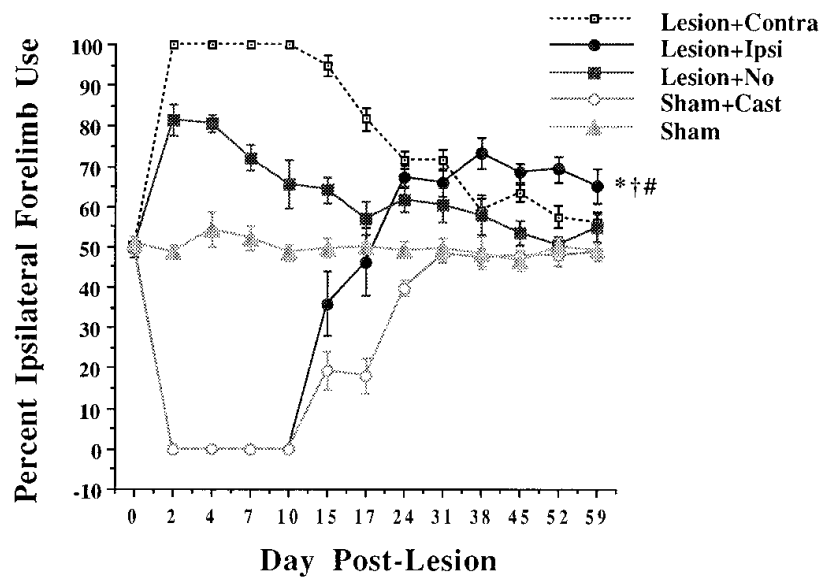

B

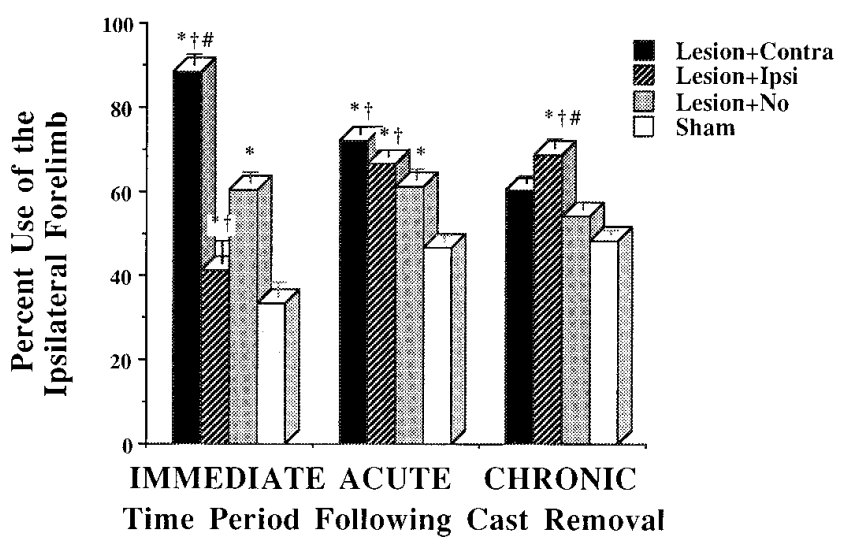

Figure 6. Asymmetry in limb use over days $(A)$ and pooled into immediate, acute, and chronic time periods after cast removal $(B)$. During casting, lesioned animals show a preference for the ipsilateral limb, which begins to become more symmetrical. Immediately after cast removal, all casted rats prefer to use the previously noncasted forelimb. Preferential use of the ipsilateral limb in both Lesion +Ipsi and Lesion + Contra casted animals is seen acutely after cast removal but is persistent in the Lesion+Ipsi group. ${ }^{*} p<0.05$, significantly different from Sham; ${ }^{\dagger} p<0.05$, significantly different from Lesion + No; ${ }^{*} p<0.05$, significantly different from either Lesion+Contra or Lesion+Ipsi.

$\sim 75 \%$ (significantly different from Lesion + No, Lesion+Contra, and Sham groups, $p<0.03$ ).

Analysis of individual behaviors in the platform suggests that the overall return to more symmetrical limb use in Lesion + No animals may be deceiving. Figure $7 A$ shows the results of percent ipsilateral limb use after landing, and Figure $7 B$ shows the results of percent ipsilateral limb use for support along the wall. Observations of the limb used for landing followed the pattern of the analysis of overall limb use, placing and extinction placing tests, and the test of somatosensory asymmetry: (1) a significantly larger, slightly longer-lasting deficit in the Lesion+Contra group compared to Lesion+No group, and (2) a significantly larger, long-lasting, and perhaps permanent deficit in the Lesion+Ipsi group compared to Lesion+Contra and Lesion+No groups. Analysis of the landing behavior in Lesion+No animals also indicated that in the chronic period after cast removal (the period of time in which Lesion + No animals show a return to more symmetrical limb use), the Lesion+No animals preferred to use the ipsilateral limb significantly less than sham animals (i.e., they preferentially used the impaired forelimb for landing).
A
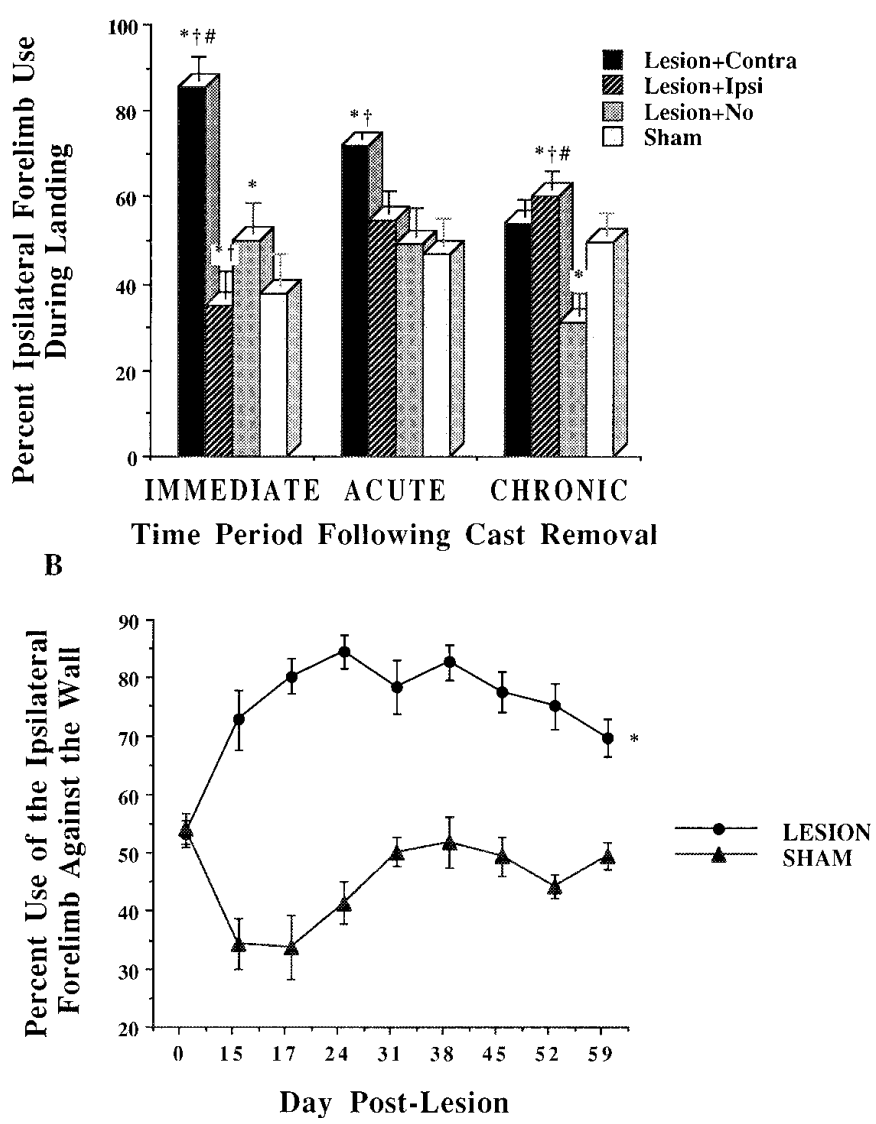

Figure 7. Asymmetries in landing on the platform $(A)$ are transiently higher in the Lesion + Contra group and significantly higher and longerlasting in the Lesion+Ipsi group. In the chronic time period, Lesion+No animals begin to preferentially use the impaired limb for landing. $B$, A significant preference for ipsilateral forelimb use along the wall is maintained throughout the experiment in all lesioned animals. *, Significantly different from Sham $(p<0.05) ; \dagger$, significantly different from Lesion + No $(p<0.05)$; \#, significantly different from Lesion + Ipsi or Lesion + Contra $(p<0.05)$.

Analysis of the wall behavior indicated that all lesioned animals preferentially used their ipsilateral forelimb for support against the wall immediately after injury and continued to do so, as late as $60 \mathrm{~d}$ postlesion (significantly different from Sham, $p<0.001$; see Fig. $7 B$ ). Furthermore, recent observations showed a deficit in this behavior in lesioned animals at $180 \mathrm{~d}$ postlesion (Kozlowski et al., 1995). Hence, symmetrical limb use in exploration of the wall may be a behavior that is permanently affected by FL-SMC lesions.

Taken together, analysis of the individual behaviors in the platform suggests that the return to symmetrical limb use previously reported in lesioned animals may reflect a redistribution of limb use tasks by the animal rather than general recovery of function. The symmetrical limb use in lesioned animals is qualitatively different from that seen in nonlesioned animals. Sham animals symmetrically use their forelimbs in all of the individual behaviors. In lesioned animals, a return to symmetrical use is seen in rearing behaviors. However, lesioned animals continue to use the ipsilateral forelimb preferentially for support along the wall and preferentially use the contralateral forelimb for landing (which, statistically, results in symmetrical limb use). Therefore, the return to symmetrical limb use in uncasted lesioned animals is 
Table 2. Activity measures of the ipsilateral versus contralatera forelimb during and after casting

\begin{tabular}{lllllll} 
& \multicolumn{2}{l}{ During casting } & & \multicolumn{2}{l}{ After casting } \\
\cline { 2 - 3 } \cline { 6 - 7 } Group & Ipsi & Contra & & Ipsi & Contra \\
\hline Lesion+Contra & $14.74(3.1)^{*}$ & $0(0)$ & & $20.7(1.6)^{\dagger}$ & $11.2(1.3)$ \\
Lesion+ Ipsi & $0(0)$ & $13.2(2.0)^{*}$ & & $21.5(2.4)^{\dagger}$ & $11.1(1.6)$ \\
Lesion+No & $21.5(2.1)^{\dagger}$ & $7.9(1.4)$ & & $18.6(2.1)^{\dagger}$ & $12.2(1.4)$ \\
Sham & $19.5(1.0)$ & $19.9(1.5)$ & & $18.8(3.7)$ & $20.5(0.8)$
\end{tabular}

Data are presented as mean \pm SE. Lesion + Ipsi animals used their impaired forelimb more than Lesion+No animals. Lesion+Contra animals used their nonimpaired forelimb less than Lesion + No animals. ${ }^{*} p<0.001$, significantly different from Lesion $+\mathrm{No} ;{ }^{\dagger} p<0.05$, significantly different from Contra forelimb.

qualitatively different from symmetry observed in sham animals. Thus, it is not a true measure of recovery but, rather, a measure of alternative, compensatory strategies. Lesion $+\mathrm{No}$ and Lesion + Contra groups successfully use these strategies, whereas Lesion+Ipsi animals do not. They continue to preferentially use the ipsilateral forelimb for all behaviors in the platform.

\section{Activity measures}

Measures of activity were obtained from observations of limb use on the platform both during the casting period and after cast removal (postcast). These measurements were taken for two main reasons. First, it was important to show that deficits in contralateral limb use were not attributable to increased activity in the ipsilateral forelimb. Second, it was important to determine that the ipsilateral cast caused overuse of the impaired forelimb relative to no-cast conditions. Because some groups were allowed to use only one limb during the casting period, separate activity measures of the ipsilateral (nonimpaired) and contralateral (impaired) limb were obtained. Differences between activity in the impaired and nonimpaired forelimb in the different treatment groups both during casting and postcast were analyzed. These measures are presented in Table 2. One-way ANOVA revealed a significant effect of Group for both use of the impaired limb and nonimpaired limb during casting $\left(F_{(3,31)}=4.58, p<0.009 ; F_{(3,30)}\right.$ $=12.30, p<0.0001$, respectively). Post hoc analyses revealed that during the casting period, casting the nonimpaired limb (Lesion + Ipsi) caused an increase in activity of the impaired limb compared to the activity of the impaired limb in Lesion + No animals $(p<0.01)$, whereas casting the impaired limb (Lesion + Contra) caused a decrease in activity of the nonimpaired limb compared to the activity of the nonimpaired limb Lesion + No animals $(p<0.01)$. However, Lesion + No animals showed the same amount of activity in the nonimpaired forelimb as did nonlesioned animals, whereas there was a lesion-induced decrease in activity of the impaired limb. Post-cast analysis revealed significantly less activity in the impaired limb in all lesion groups, compared to sham, but no significant differences in activity of the nonimpaired forelimb. Therefore, deficits in limb use cannot be attributed to an increase in use of the ipsilateral limb but, rather, to a decreased use of the contralateral, impaired limb (which altered the types of movements required by the nonimpaired limb; see Jones and Schallert, 1994). Also, behavioral and anatomical differences between groups after removal of the cast may be related to the use of their forelimbs during the casting period.

\section{DISCUSSION}

\section{Long-term behavioral consequences of forelimb immobilization in animals with unilateral FL-SMC lesions}

Immobilizing the ipsilateral forelimb in lesioned animals (forcing use of the impaired limb) resulted in severe and long-lasting behavioral deficits after cast removal in all of the behaviors measured: contralateral forelimb placing, responsiveness to forelimb somatic-sensory stimulation, and forelimb use for posturalmotor support, which did not recover to noninjured (sham) levels. Immobilizing the contralateral forelimb in lesioned animals (preventing use of their impaired forelimb) resulted in slightly larger and longer-lasting behavioral deficits after cast removal (compared to noncasted, lesioned animals), which did recover to sham levels. Immobilization of a single forelimb in sham rats resulted in no significant behavioral changes.

Both behavioral and anatomical explanations for these data may be relevant. Studies have shown that functional recovery may be attributable to the development of alternate strategies involving compensatory behaviors (Honzick, 1936; Castro, 1977; Whishaw et al., 1986, 1991; Schallert, 1988). Lesion+No animals, which were allowed to use both forelimbs, may have developed the most efficient compensatory strategies and thus had the smallest, shortest-lasting deficits. The deficits seen in lesioned animals with contralateral forelimb immobilization may be a result of disuse of the impaired limb during the early postlesion period, i.e., missed therapeutic windows of opportunity. Moreover, in these animals the nonimpaired limb was not used to the same extent as in Lesion+No animals. The most surprising result was that immobilization of the ipsilateral (nonimpaired) forelimb, which would cause an increase in the use of the impaired forelimb, resulted in the largest behavioral deficits and the longest recovery period. This cannot be attributable to a lack of use of the impaired limb. In fact, Lesion + Ipsi animals used their impaired forelimb more than nonimmobilized, lesioned animals. It is possible that these deficits may be caused, in part, by lack of use of the ipsilateral forelimb as a "crutch" to compensate for deficits in the impaired forelimb during the early postlesion period. Indeed, recent work in this laboratory by R. Cocke, D. Kozlowski, J. Gotts, and T. Schallert (unpublished data) showed that in noncasted animals that appeared to have recovered from sensorimotor impairments, anesthetization of the ipsilateral, nonimpaired (crutch) forelimb reinstated severe impairments in the use of the impaired forelimb, whereas anesthetization of the impaired forelimb had little or no effect. However, this does not explain fully why the Lesion+Ipsi animals showed such a dramatic and long-lasting deficit compared to Lesion + Contra and Lesion + No groups. This may be explained neuroanatomically.

\section{Long-term anatomical consequences of forelimb immobilization in animals with unilateral FL-SMC lesions}

\section{Prevention of dendritic plasticity}

Preventing animals from using their nonimpaired limb during the early postlesion period resulted in a blocking of the usedependent increase in dendritic growth of layer $\mathrm{V}$ pyramidal neurons in the contralateral, homotopic cortex (as in Jones and Schallert, 1994). After removal of the cast, there was a slight but not significant increase in dendritic growth, consistent with the possibility of an optimal period, or window of opportunity, for lesion-induced, use-dependent dendritic arborization. The reason for the lack of reinstatement in dendritic plasticity may be behav- 
ioral. After removal of the cast, Lesion+Ipsi animals used their forelimbs asymmetrically, preferring to use their ipsilateral forelimb more than their contralateral forelimb, as do nonimmobilized lesioned animals immediately after surgery. However, in Lesion+Ipsi animals there was not a progression toward symmetrical limb use, as seen during the first $18 \mathrm{~d}$ postlesion in nonimmobilized animals. Thus, arborization may be attributable to the learning of compensatory strategies required for symmetrical limb use and not just to preferential use of the ipsilateral forelimb (Jones and Schallert, 1994). Greenough and colleagues have shown that learning, and not activity alone, is necessary for dendritic plasticity (Black et al., 1990, 1991; Greenough and Anderson, 1991). On the other hand, the reason for the prevention of dendritic plasticity may be more neuroanatomical. Immobilization of the nonimpaired limb may have prevented the astrocytic expansion seen in the FL-SMC of the intact hemisphere after injury, which has been postulated to play a role in dendritic plasticity by providing trophic support to prime for growth (Jones and Schallert, 1992). Additionally, it may be possible that the exaggeration of neural injury may have played a role in the prevention of dendritic growth.

\section{Exaggeration of lesion size}

The chronic, long-lasting behavioral deficits are also likely to be attributable to the dramatic exaggeration of the lesion seen in ipsilaterally immobilized animals. Immobilization of the forelimb ipsilateral to the lesion resulted in a dramatic increase in the extent of the volume of the lesion. It may be that forced overuse of the impaired forelimb caused chronic excitation of surviving tissue surrounding the lesioned area, which in turn resulted in a dramatic deterioration of the lesioned hemisphere. To our knowledge, this is the first report that behavioral events can exaggerate brain damage. It has been demonstrated, however, that in noninjured neural systems chronic depolarization produces retraction of and degeneration of phasic motor axons in the developing crayfish (Egid and Lnenicka, 1994) and that unilateral electrical stimulation of the sensorimotor cortex induces excitotoxic loss of GABAergic neurons in the striatum of rats (To et al., 1994).

\section{Possible mechanisms for use-dependent exaggeration of neuronal injury}

A number of possibilities exist (some of which are being currently examined) that may explain the mechanism behind use-dependent exaggeration of neuronal injury. The increase in lesion size might be attributable to behaviorally related enhancement of excitotoxic processes. Use-dependent increases in depolarization of glutamatergic neurons may result in an excitotoxic cascade, causing an increased flux of $\mathrm{Ca}^{2+}$ via glutamatergic action at NMDA receptors, which may eventually lead to neuronal death (Olney, 1983; Schwarcz et al., 1984; Choi et al., 1987; Choi, 1988; Cotman et al., 1988; Mattson, 1989; Mattson et al., 1989, 1993). If this is the case, then administering an NMDA-receptor antagonist (such as MK801) during the time in which the animal's limb is immobilized may prevent the deterioration of the lesion and the chronic and long-lasting behavioral deficits. This possibility is currently being explored by J. Humm, R. Cocke, and T. Schallert (unpublished data), and preliminary data indicate that MK-801 prevents usedependent exaggeration of neural injury.

Forced use of the impaired limb may mimic peri-infarct events seen in the penumbra of ischemia (Nedergaard and Astrup, 1986; Gill et al., 1992; Iijima et al., 1992). Ischemic insults produce a focal lesion as well as an area of undamaged, yet vulnerable, neural tissue called the penumbra, which is characterized by the presence of spreading depression. In ischemia, there are two types of spreading depression-like depolarizations: one mediated by glutamate released from the core of the infarct (classical glutamate excitotoxicity), and one mediated by fluctuations of blood flow that result in transient episodes of hypoxia (Nedergaard and Hansen, 1993; Back et al., 1994). The hypoxia compromises protein synthesis and can result in progressive tissue injury and the expansion of the ischemic infarct core into the penumbral zone (Mies et al., 1991). It may be that forcing the use of the impaired limb results in spreading depression-like depolarizations that may lead to transient episodes of hypoxia in otherwise surviving, but vulnerable, tissue surrounding the lesioned area. The hypoxia may induce metabolic deficiency such as an inhibition of protein synthesis which, in turn, may produce the progressive neural damage seen in ipsilaterally casted animals.

On the other hand, it may be that a hypermetabolism, instead of a hypometabolism, is the cause. Studies have shown that animals that are placed in enriched environments (Black et al., 1991) or that engage in sustained motor activity, such as exercise (Black et al., 1990), have a significantly higher vascular density than nonenriched, nonactive rats so as to deal with the metabolic demand placed on them. In a compromised brain, however, initiation of these events may be deleterious. Increased or fluctuations in blood flow, hemorrhage, or increased intracranial pressure may act synergistically to cause permanent histological damage (i.e., expansion of the size of the lesion). Studies examining cerebral blood flow, protein synthesis, and oxidative and glucose metabolism in the lesioned area of ipsilaterally casted animals are currently being implemented to address these questions.

Finally, it was also hypothesized that the stress of immobilization may play a role. Animals that are being forced to use their impaired limb may be experiencing more stress than animals that are being forced to use their nonimpaired limb. It is well documented that stress causes an increase in glucocorticoids in the brain (for review, see Sapolsky, 1992) that has been linked to cell death in the hippocampus (Sapolsky and Pulsinelli, 1985) and the neocortex (Koide et al., 1986), presumably caused by the induced increase in excitatory amino acids (Moghaddam, 1993; Moghaddam et al., 1994). The role of stress is currently being explored, and preliminary results indicate that the level of corticosterone in animals with ipsilateral limb immobilization is not different from that of animals with contralateral limb immobilization or no limb immobilization (Kozlowski et al., 1995). Therefore, increased corticosterone levels per se do not seem to play a direct role in the exaggeration of neuronal injury.

\section{Relationship between behavioral and anatomical consequences of forelimb immobilization}

Regardless of the mechanism, the present study indicates that immobilization of the nonimpaired limb (i.e., forcing the use of the impaired limb) results in chronic and long-lasting behavioral asymmetries, disruption of neural plasticity in the intact hemisphere, and a dramatic exaggeration of neural injury in the lesioned hemisphere. At this time, it is not possible to determine whether the devastating behavioral effects of casting the nonimpaired limb are linked to the prevention of dendritic overgrowth, caused by the progressive expansion of the lesion size, or both.

To delineate the contributions of the anatomical consequences of limb immobilization to the behavioral deficits, studies must be 
performed to isolate further the optimal periods for dendritic growth and use-dependent exaggeration of injury.

\section{Analysis of forelimb use as a measure of behavioral compensation}

Finally, this study resulted in an interesting observation regarding the measurement of asymmetrical limb use on a three-sided platform. Analysis of individual behaviors in the platform suggested that the return to symmetrical limb use seen in lesioned animals was qualitatively different from symmetrical limb use in nonlesioned animals. The symmetrical limb use seen in nonlesioned animals was attributable to equal use of both forelimbs in all of the behavioral measures. In contrast, the symmetrical limb use seen in "recovered" lesioned animals consisted of a preference for the ipsilateral forelimb on one behavior (for support against the wall) and an opposing preference for the contralateral forelimb on another behavior (landing on the platform after a rear or after exploration of the wall). Thus, the symmetrical limb use seen in lesioned animals represents an alternative, compensatory strategy used by the lesioned animals that is not analogous to the symmetrical forelimb use of nonlesioned animals. These findings have resulted in the development of new hemisphere-specific behavioral tests and manipulations to examine the compensatory use of the ipsilateral forelimb in lesioned animals (Schallert and Kozlowski, 1996).

\section{Implications}

The potential implications for rehabilitation suggested by this study may be worth noting, albeit with the usual caution about generalizing from one lesion model to others and about comparing animal research with human neurological treatment. This study, in conjunction with previous studies (Jones and Schallert, 1992, 1994), suggests that after brain injury there may exist (1) a window of opportunity for compensatory, usedependent structural changes in the intact cortex, and (2) a region of sublethally injured, but use-vulnerable, tissue in the injured hemisphere. Although behavioral experience can enhance neuronal growth after brain injury in remote, intact brain areas, excessive behavioral pressure during the early postlesion period may cause irreversible damage to surviving, but compromised, tissue surrounding the injury. Therefore, a "use-itearly-or-lose-it" strategy of rehabilitation that was implied in Jones and Schallert $(1992,1994)$ may apply to the intact hemisphere but not to the injured hemisphere. Instead, a less aggressive "use-it-but-don't-overuse-it" strategy perhaps should be adopted for optimal restoration of function of the forelimb corresponding to the injured hemisphere.

\section{REFERENCES}

Back T, Kohno K, Hossmann K-A (1994) Cortical negative DC deflections following middle cerebral artery occlusion and $\mathrm{KCl}$-induced spreading depression: effect on blood flow, tissue oxygenation, and electroencephalogram. J Cereb Blood Flow Metab 14:12-19.

Black JE, Isaacs KR, Anderson BJ, Alcantara AA, Greenough WT (1990) Learning causes synaptogenesis, whereas motor activity causes angiogenesis, in cerebellar cortex of adult rats. Proc Natl Acad Sci USA 87:5568-5572.

Black JE, Zelazny AM, Greenough WT (1991) Capillary and mitochondrial support of neural plasticity in adult rat visual cortex. Exp Neurol 3:204-209.

Castro AJ (1977) Limb preferences after lesions of the cerebral hemisphere in adult and neonatal rats. Physiol Behav 18:605-608.

Choi DW (1988) Calcium-mediated neurotoxicity: relationship to specific channel types and role in ischemic damage. Trends Neurosci $11: 465-469$
Choi DW, Maulucci-Gedde MA, Kriegstein AR (1987) Glutamate neurotoxicity in cortical cell culture. J Neurosci 7:357-368.

Cotman CW, Monaghan DT, Ganong AH (1988) Excitatory amino acid neurotransmission: NMDA receptors and Hebb-type synaptic plasticity. Annu Rev Neurosci 11:61-80.

Egid K, Lnenicka GA (1994) Differential effects of depolarization on the survival and growth of two populations of motorneurons in culture. Soc Neurosci Abstr 20:281.

Gill R, Andine P, Helered L, Personn L, Hagberg H (1992) The effect of MK-801 on cortical spreading depression in the penumbral zone following focal ischemia in the rat. J Cereb Blood Flow Metab 12:371-379.

Greenough WT, Anderson BJ (1991) Cerebellar synaptic plasticity, relation to learning versus neural activity. Ann NY Acad Sci 627:231-247.

Gundersen HGJ, Jensen EB (1987) The efficiency of systematic sampling in stereology and its prediction. J Microsc 147:229-263.

Hall RD, Lindholm EP (1974) Organization of motor and somatosensory neocortex in the albino rat. Brain Res 66:23-38.

Honzik CH (1936) The sensory basis of maze learning in rats. In: Brain damage and recovery: research and clinical perspectives (Finger D, Stein DG, eds). New York: Academic.

Iijima T, Mies G, Hossmann K-A (1992) Repeated negative deflections in rat cortex following middle cerebral artery occlusion are abolished by MK-801: effect on volume of ischemic injury. J Cereb Blood Flow Metab 12:737-733.

Jones TA, Schallert T (1989) Sensorimotor cortex lesions: timedependent anatomical changes specific to the contralateral homotopic cortex. Soc Neurosci Abstr 15:1223.

Jones TA, Schallert T (1992) Overgrowth and pruning of dendrites in adult rats recovering from neocortical damage. Brain Res 581:156-160.

Jones TA, Schallert T (1994) Use-dependent growth of pyramidal neurons after neocortical damage. J Neurosci 14:2140-2152.

Jones TA, Kleim JA, Greenough WT (1995) Neuronal growth contralateral to unilateral sensorimotor cortex damage in adult rats: a quantitative electron microscopic examination. Soc Neurosci Abstr 182:10.

Jones TA, Kleim JA, Greenough WT (1996) Synaptogenesis and dendritic growth in the cortex opposite unilateral sensorimotor cortex damage in adult rats: a quantitative electron microscopic examination. Brain Res, in press.

Koide T, Wielock T, Siesjo B (1986) Chronic dexamethasone pretreatment aggravates ischemic neuronal necrosis. J Cereb Blood Flow Metab 6:395.

Kolb B (1995) Brain plasticity and behavior. Mahwah, NJ: Lawrence Erlbaum.

Kolb B, Tees RC (1990) The cerebral cortex of the rat. Cambridge: MIT.

Korbo L, Pakkenberg B, Ladefoged O, Gundersen HJG, Arlien-Soborg P, Pakkenberg H (1990) An efficient method for estimating the total number of neurons in rat brain cortex. J Neurosci Methods 31:93-100.

Kozlowski DA, Jones TA, Schallert T (1994) Pruning of dendrites and maintenance of function after brain damage: role of the NMDA receptor. Restor Neurol Neurosci 7:119-126.

Kozlowski DA, Humm JL, Krepps A, Cocke R, James DC, Schallert T (1995) Use-dependent exaggeration of brain damage: vulnerable periods, behavioral effects, and corticosteroid analysis. Soc Neurosci Abstr 21:73.

Mattson MP (1989) Cellular signaling mechanisms common to the development and degeneration of neuroarchitecture: a review. Mech Aging Dev. 50:103-157.

Mattson MP, Guthrie PB, Kater SB (1988) Intracellular messengers in the generation and degeneration of hippocampal neuroarchitecture. J Neurosci Res 20:447-464.

Mattson MP, Rydel RE, Leiberburg I, Smith-Swintosky VL (1993) Altered calcium signaling and neuronal injury: stroke and Alzheimer's disease as examples. In: Markers of neuronal injury and degeneration (Johannessen JN, ed), pp 1-21. New York: New York Academy of Sciences.

Mies G, Ishimaru S, Xie Y, Seo K, Hossmann K-A (1991) Ischemic thresholds of cerebral protein synthesis and energy state following middle cerebral artery occlusion in rat. J Cereb Blood Flow Metab 11:753-761.

Moghaddam B (1993) Stress preferentially increases extraneuronal levels of excitatory amino acids in the prefrontal cortex: comparison to hippocampus and basal ganglia. J Neurochem 60:1650-1657.

Moghaddam B, Bolinao ML, Stein-Behrens B, Sapolsky R (1994) Glucocorticoids mediate the stress-induced extracellular accumulation of glutamate. Brain Res 655:251-254. 
Neafsey EJ, Bold EL, Haas G, Hurley-Guis KM, Quirk G, Sievert CF, Terreberry RR (1986) The organization of the rat motor cortex: a microstimulation mapping study. Brain Res Rev 11:77-96.

Nedergaard M, Astrup J (1986) Infarct rim: effect of hyperglycemia on direct current potential and $\left[{ }^{14} \mathrm{C}\right] 2$-deoxyglucose phosphorylation. J Cereb Blood Flow Metab 6:607-615.

Olney JW (1983) Excitotoxins: an overview. In: Excitotoxins (Fuxe K, ed). London: Macmillan.

Ramon-Moliner E (1970) The Golgi-Cox technique. In: Contemporary research methods in neuroanatomy (Nauta WJH, Ebbesson SOE, eds), pp 32-55. New York: Springer.

Royet JP (1991) Stereology: a method for analyzing images. Prog Neurobiol 37:433-474.

Rose FD, Davey MJ, Love SL, Dell PA (1987) Environmental enrichment and recovery from contralateral sensory neglect in rats with large unilateral neocortical lesions. Behav Brain Res 24:195-202.

Sapolsky RM (1992) Stress, the aging brain, and the mechanisms of neuron death. Cambridge: MIT.

Sapolsky RM, Pulsinelli W (1985) Glucocorticoids potentiate ischemic injury to neurons therapeutic implications. Science 229:1397.

Schallert T (1988) Aging-dependent emergence of sensorimotor dysfunction in rats recovered from dopamine depletion sustained early in life. In: Central determinants of age-related decline in motor function (Joseph JA, ed), pp 108-120. New York: New York Academy of Science.

Schallert T, Jones TA (1994) "Exuberant" neuronal growth after brain damage in adult rats: the essential role of behavioral experience. J Neural Trans Plast 4:193-198.

Schallert T, Kozlowski DA (1996) Brain damage and plasticity: userelated enhanced neuronal growth and overuse-related exaggeration of injury. In: Cerebrovascular diseases (Ginsberg MD, ed). New York: Blackwell Science, in press.

Schallert T, Whishaw IQ (1984) Bilateral cutaneous stimulation of the somatosensory system in hemidecorticate rats. Behav Neurosci 98:518-540.

Schallert T, Upchurch M, Logaugh N Farrar SB, Spirduso WW, Gilliam P, Vaughn DM, Wilcox RE (1983) Tactile extinction: distinguishing between sensorimotor and motor asymmetries in rats with unilateral nigrostriatal damage. Pharmacol Biochem Behav 16:455-462.

Schwarcz R, Foster AC, French ED, Whetsell WO, Kohler C (1984) Excitotoxic models for neurodegenerative disorders. Life Sci 35:19-32.

To T, Anton B, Evan CJ, Maidment NT (1994) Chronic cortico-striatal glutamatergic activation induces a slowly progressing striatal lesion. Neurosci Abstr 20:427.

Uylings HBM, VanEden CG, Hoffman MA (1986) Morphometry of size/ volume variables and comparison of their bivariate relations in the nervous system under different conditions. J Neurosci Methods 18:19-37.

West MJ, Gundersen HJG (1990) Unbiased stereological estimation of the number of neurons in the human hippocampus. J Comp Neurol 296:1-22.

Whishaw IQ, O'Conner WT, Dunnett ST (1986) The contributions of motor cortex, nigrostriatal dopamine and caudate-putamen to skilled forelimb use in the rat. Brain 109:805-843.

Whishaw IQ, Pellis SM, Gorny BP, Pellis VC (1991) The impairments in reaching and the movements of compensation in rats with motor cortex lesions: an endpoint, videorecording, and movement notation analysis. Behav Brain Res 42:77-91.

Wise SP, Donoghue JP (1986) Motor cortex of rodents. In: Cerebral cortex, Vol 5 (Jones EG, Peters A, eds), pp 243-270. New York: Plenum. 